\title{
EL HECHO RELIGIOSO COMO HECHO SOCIAL: IMPLICANCIAS PARA EL ESTADO OCCIDENTAL
}

\author{
MARCELA BORDÓN LUGO ${ }^{1}$
}

\begin{abstract}
Resumen:
Partiendo de un enfoque teórico sobre el significado e identificación del hecho religioso, comenzamos el análisis sobre su relevancia para el Estado, comprendido éste desde su concepción moderna y occidental. Con esto, se busca proponer un enfoque al concepto de "Estado Laico", considerado como la modalidad en auge en nuestros tiempos sobre cómo el Estado debería interactuar con el hecho religioso.

Palabras claves: hecho religioso, hecho social, Estado moderno, Estado Laico
\end{abstract}

\begin{abstract}
:
Starting from a theoretical focus on the meaning and identification of the religious fact, we begin the analysis of its relevance for the State, understood from its modern and western conception. With this, it seeks to propose an approach to the concept of "Lay State", considered as the booming modality in our times on how the State should interact with the religious fact.
\end{abstract}

Keywords: religious fact, social fact, modern state, secular state

DOI: $10.7764 /$ RLDR.9.116

\section{INTRODUCCIÓN}

Partiendo desde una aproximación teórica sobre qué es y cómo podemos identificar al hecho religioso, nos adentramos al análisis acerca de cuál es su relevancia ante el Estado, en su concepción moderna y occidental. Este escenario es analizado en el presente trabajo, buscando proponer un acercamiento al concepto de Estado Laico, considerado como la modalidad en auge en nuestros tiempos sobre cómo debe interactuar el Estado con el hecho religioso.

En este análisis, el hecho religioso no se circunscribe a la institución de "la iglesia" únicamente, aunque la expresión es utilizada comúnmente en ese sentido; sino como un fenómeno social que se mantiene vigente y actual en la realidad de la ciudadanía de los países del mundo.

\footnotetext{
${ }^{1}$ Abogada por la Universidad Nacional de Asunción, Paraguay. Magíster (C) en Ciencias Políticas por la Pontificia Universidad Católica de Chile. Email: mabordon@uc.cl
} 
Marcela Bordón Lugo: El hecho religioso como hecho social: implicancias para el Estado occidental.

\section{ANTECEDENTES}

La relación entre el estado y la religión representa uno de los ámbitos de debate más complejos desde que la separación de ambas instituciones dividió naciones, entre quienes respondían a determinada Iglesia, al Rey o a la autoridad suprema de una nación.

Ante la separación del Estado y la Iglesia en la Europa del siglo XVII y XVIII como producto de la llustración y las consecuentes aspiraciones independentistas y antimonárquicas, la Iglesia Católica, en este contexto como una de las instituciones religiosas de mayor influencia en el antiguo continente, se vio en algunos aspectos limitada y seriamente cuestionada acerca de sus atribuciones de autoridad en la estructura del Estado.

En esta era moderna de la historia de la civilización se rememoran acontecimientos como el surgimiento de nuevas estructuras políticas, inspiradas muchas de ellas en la revolución francesa o la revolución inglesa, así como en el nuevo continente se ve florecer el ideal independiente y descolonizador con las diversas contiendas independentistas que se extendieron de norte a sur de las Américas. En este contexto, la religión comenzó a ser estudiada más como un fenómeno social, haciendo así que pensadores de áreas como la sociología, antropología y filosofía buscaran describir y definir a esta nueva entidad que continuó desarrollándose y acomodándose a su realidad temporal en medio de las nuevas leyes y orden social que determinada las nuevas limitaciones y alcances de la religión a través de la iglesia.

\section{El hecho religioso como un hecho social}

Para acercarnos a una comprensión moderna de la manera en que el Estado y la religión se interrelacionan es importante primeramente adentrarnos en el concepto de lo que es un hecho religioso.

En este sentido, la sociología como ciencia que estudia el comportamiento de la sociedad nos aporta con análisis realizados por clásicos referentes de dicha área de las ciencias sociales. Para fines de este estudio, comenzaremos mencionando algunos postulados propuestos Emile Durkheim, atendiendo a que su propuesta de estudiar a las religiones fue el punto de partida para el surgimiento de una de las áreas especializadas del estudio de la sociología, cual es la sociología de la religión.

Durkheim, conocido también como una referencia en el estudio de la sociología jurídica, es uno de los primeros en abordar la cuestión de la religión desde la sociología a través de su 
publicación "El suicidio" (1897). En esta obra presenta como la identidad religiosa es reconocida como una variable determinante al momento de buscar comprender el accionar humano.

Esta afirmación se desarrolla más claramente en "Las formas elementales de la vida religiosa" (1912), publicación en el cual identifica la existencia de dos formas de organización religiosa. La primera, "las formas elementales" que son propias de las sociedades donde impera una estructura comunitaria donde se desarrolla lo que llama una "solidaridad mecánica"; y la segunda forma, la "compleja", aquella desarrollada por la sociedad con una amplia visión del trabajo, donde impera la "solidaridad orgánica".

Aquí es donde se menciona como un concepto teórico que la religión es "un hecho social", en sus términos afirma Durkheim que la religión es "una realidad sui géneris".

El hecho religioso transciende así, de acuerdo con el análisis de Durkheim, de una dimensión subjetiva particular de los practicantes y es evidente de acuerdo con sus conclusiones, que la comprensión de este hecho religioso es mayor y más poderoso que sus mismos practicantes porque es impuesta y determinada por sí mismo hacia estos.

En la experiencia de Durkheim estudiando comunidades religiosas "primitivas" en Australia, afirmó que estas representaban incluso características de aquellas consideradas avanzadas. Sostiene que los fieles creyentes de un culto o religión no tienen una visión privilegiada de los motivos que los conducen a desarrollar comportamientos que se identifican con prácticas de determinado culto.

En palabras del autor, "realidad que las mitologías se han representado de tantas formas distintas, pero que es la causa objetiva, universal y eterna de las sensaciones sui generis que constituyen la experiencia religiosa, es la sociedad (...) Ella es la que lo eleva por encima de sí mismo; ella es incluso la que lo hace, pues lo que hace al hombre es ese conjunto de bienes espirituales que conforma la civilización, y la civilización es la obra de la sociedad" (Del Picó. 2018). De esta forma, se afirma también el enunciado que expresa que la exterioridad y coerción de la religión se manifiesta en determinada acción que domina la vida religiosa, y sólo la acción puede ser producto de la sociedad.

Otro autor que se refirió a esto es Peter Berger en su texto "El dosel sagrado" (1971), en el cual afirma que todo sistema religioso es producto de una actividad humana, y nada más que eso. Esta expresión sugiere que no se le podría atribuir ningún otro origen al hecho religioso, sino 
Marcela Bordón Lugo: El hecho religioso como hecho social: implicancias para el Estado occidental.

que la iniciativa del mismo ser humano y de su actividad, como respuesta eventual a una necesidad de sentido de la existencia propia y del universo. Esto podría leerse de dos maneras: que "el hombre inventó a Dios y a las religiones", o bien, palabras de Luiggi Giussani "que el hombre es el que emprende el camino de búsqueda de sentido, mirando más allá que las explicaciones naturales que tiene al alcance", enfoque que hoy sigue siendo válido. (Giussani. 1988).

Retomando la propuesta de Durkheim, este formuló que las fuerzas religiosas son fuerzas morales, y como todo sentimiento moral actúa como elemento de cohesión social. La fuerza moral de un grupo social es la realidad sui géneris que señalamos más arriba. Como todo sentimiento colectivo, según Durkheim, que para poder tomar conciencia del "yo", debe fijarse en cosas externas a uno mismo, las fuerzas morales de la religiosidad toman prestado sus elementos esenciales de la conciencia individual. ${ }^{2}$

Los autores Berger y Luckmann (1968) que desarrollan esta propuesta de Durkheim, afirman que todo conocimiento es un producto social que alcanza un estatus de factibilidad en condiciones sociales determinadas, es decir, el conocimiento y la verdad que se forman en base al hecho religioso, solo tendrán consecuencias reales en el contexto social en el que son validadas.

Podemos decir así que dicho conocimiento y verdad basados en el hecho religioso se "objetiva" al adquirir vida propia independiente de sus creadores, hasta el punto de reaccionar sobre sus practicantes determinando, sometiendo y constituyéndose en la mencionada realidad "sui géneris". Esto se configura al momento que el individuo toma una identidad propia, que trasciende el fenómeno cultural, incluso podríamos decir "folklórico". La forma de expresar lo religioso es cultural, pero el fundamento de esa creencia es cosmogónico, anterior a la cultura. Lo sagrado, que en su forma primitiva se constituye como "el mito", es un hecho compartido por toda la humanidad, intrínseco a ella, por sobre los determinantes culturales (Bentué, 2004). Quizás este último punto puede ser considerado como un hecho sociológico, pero sólo puede abordarlo desde una perspectiva ex post, fenoménica, no preguntándose por las causas del mismo, que exceden su objeto de estudio.

Esta realidad particular, que necesita ser analizada en su contexto, demuestra cómo se pone en evidencia la existencia de un mayor grado de cohesión social en su contexto religioso

\footnotetext{
${ }^{2}$ En el contexto de este análisis, no se considera necesario hacer un juicio de valor si esta interpretación puede ser considerada "buena" o "mala", atendiendo a que es el surgimiento de este interés por la teorización sociológica sobre el fenómeno del hecho religiosa lo que nos propone esta lectura y línea de análisis.
} 
ISSN 0719-7160

comunitario. Atendiendo que la identidad y el sentido de pertenencia, nuevamente recordamos, que va más allá de la subjetividad de los practicantes, provoca un acontecimiento, un hecho social evidente, cohesionado por sus propios valores, principios y prácticas que se vuelven verdad actual y racional para aquellos que la viven en su interioridad (subjetivamente) como externa y comunitariamente (objetivamente).

\section{La relevancia del hecho religioso en su dimensión jurídica}

El hecho religioso, como hemos podido ver previamente, se ha despojado a lo largo del análisis de los teóricos de ese velo que lo enclaustraba al ámbito exclusivamente privado por considerarse la relación del individuo con la religión como una dimensión subjetiva y ajena a la realidad y a sus consecuencias objetivas en la sociedad.

Históricamente la relevancia jurídica del hecho religioso primeramente se funda en su reconocimiento como fuente material u origen social del derecho en una sociedad plural. (Del Picó, 2018). La teoría jurídica reconoce a la religión históricamente como fuente formal e interpretativa de las normas que han nacido de este contexto.

El hecho religioso es reconocido de este modo por ser uno de los elementos que permiten comprender el surgimiento y contenido de variedad de leyes vigentes hasta nuestros días, que, aunque en su génesis tiene una motivación o fundamento religioso, la adhesión cultural de determinados valores y principios, hacen que ciertas normas trasciendan el marco de lo estrictamente "religioso". De esta manera se pueden apreciar normas que moderan o regulan ciertas conductas individuales en la sociedad como son aquellas que recogen valores como la protección de la vida, la integridad del ser humano, la disciplina legal de la familia entre otros.

Otra dimensión de esta relevancia del hecho religioso en el ámbito jurídico es la repercusión que ésta ha tenido en cuanto a su reconocido como un actor relevante en el sistema político democrático, eso se ve plasmado en el reconocimiento del aporte sustantivo de la religión (o religiones) a la sociedad en su formación y como formador de la estructura fundamental de la sociedad.

Podemos citar como ejemplo a los regímenes políticos más antiguos tuvieron un sustento religioso, desde los Faraones en el antiguo Egipto afirmando que eran hijos del Dios Sol y que eran Dioses en vida, hasta los Reyes católicos que con al ser ungidos por el Papa eran considerados elegidos por el Dios cristiano. Ahora bien, la separación Iglesia-Estado es un 
Marcela Bordón Lugo: El hecho religioso como hecho social: implicancias para el Estado occidental.

fenómeno que estamos analizando en un contexto moderno, que la Iglesia católica, por ejemplo, se adhiere después de ser impuesta por la imposición secular de los diferentes procesos políticos que generaron esa separación. La Iglesia Católica se adhiere a esa separación al darse cuenta de que su dimensión totalizante se da más bien a nivel espiritual de los creyentes, no a nivel de un sistema político que intente emular, de manera muy imperfecta y distorsionada, el "Reinado Social de Cristo", junto con otros ejemplos como la forma en que, de alguna manera, el Islam también tomó esta idea cuando funda sus regímenes políticos en la Sharia o Ley Islámica. Turquía e Irán pre-Jomeini son los primeros países islámicos que establecen esta separación. También, en menor medida, el estado israelí es un ejemplo de no separación Religión-Estado.

El hecho religioso, podríamos decir, requiere del individuo también un posicionamiento, que puede generar una adhesión individual junto a una cohesión comunitaria, como puede también ser carente de adhesión a una religión o creencia determinada. El ateísmo y el gnosticismo, si bien no podríamos decir que son religiones puntualmente, o al menos no es muy común ver que generen cierta cohesión comunitaria, son posicionamientos de los individuos sobre el hecho religioso. Atendiendo a esta salvedad, debemos reconocer que también existen Estados que se constituyen de forma atea (China, Norcorea), o indiferentes al hecho religioso (Uruguay, y en menor medida, Francia. España aspira a eso también). No obstante, a mi juicio, negar el hecho religioso en la construcción social es parcelar la realidad del individuo, porque incluso la increencia es parte del mismo hecho religioso.

El hecho religioso, podemos ver como toma un rol importante en la construcción de la sociedad y la estructura del estado, ya no como fundación misma del poder o autoridad del Estado (como si lo fue en la Europa medieval por dar un ejemplo) sino como elemento que se funda en la adhesión voluntaria del individuo a una identidad religiosa.

Esta adhesión misma genera una cohesión con un colectivo de personas que pasa de una dimensión estrictamente subjetiva y personal, a una materialmente objetiva y relevante en la adopción de los valores democráticos de una nación. Muchos de los valores y principios de convivencia social tienen un fuerte sustrato en el cristianismo para la cultura occidental, por ejemplo. Las primitivas comunidades cristianas elegían a sus representantes, tenían una economía básica solidaria, etc. Posteriormente, el desarrollo del comercio, de la legislación, etc., tomaron mucho fundamento del cristianismo occidentalizado con la incorporación de elementos grecorromanos. La religión en sí no contribuye automáticamente a la democracia, pero la democracia ha de reconocer que es menos democrática sin el hecho religioso, al cercenar algo 
ISSN 0719-7160

que es tan propio de lo humano desde sus orígenes, y que le ha aportado a su desarrollo valórico y de ordenamiento social.

Así es que, ante este hecho social históricamente relevante para la construcción de un orden social y jurídico, sin ser parte de la estructura del Estado, necesita ser reconocido y protegido en su legalidad. Así es como la dimensión individual encuentra su correlato a nivel colectivo, al instituirse como derecho constitucional del reconocimiento civil de la organización religioso, su libre práctica y expresión.

La mayor parte de los países caracterizados por los valores democráticos occidentales reconocen al hecho religioso como un hecho a ser garantizado a través de la libertad religiosa, de expresión y de libre asociación. Estos se presentan como componentes esenciales que caracterizan a un "Estado Laico". De acuerdo con Puyol (2014), un Estado Laico asume como un principio fundamental el respeto a la pluralidad moral y religiosa en el interior de sus límites, comprometiéndose así a tutelar la libertad religiosa de sus miembros y la neutralidad del propio Estado en los asuntos religiosos.

\section{Distinción entre laicidad y laicismo}

Recapitulando el análisis propuesto al inicio de este trabajo, nos adentramos al escenario que nos confronta cotidianamente cuando nos disponemos a pensar en cual es o debería ser la relación entre el Estado y la religión.

Cabe la salvedad y esclarecer cuanto sea necesario, que hoy día hablar de una separación Estado-Iglesia no se circunscribe únicamente a la Iglesia Católica, incluso yendo más allá, no sólo a la/las iglesias cristianas, evangélicas o protestantes.

La separación Estado-Iglesia conlleva consigo la separación de dos instituciones, la del Estado como garante de derechos y las iglesias o cosmovisiones, expresiones de fe. Este es un aporte puntual de este análisis considerando que la globalización y el fenómeno de la migración nos esta encaminando a nuevas sociedades plurales, diversas en cuanto a religión, prácticas y tradiciones.

Retomando nuestra recopilación teórica, podemos decir que según autores contemporáneos, por laicidad se ha entendido una categoría política de carácter democrático que admite la participación de los agentes religiosos en la vida pública, imponiendo restricciones 
Marcela Bordón Lugo: El hecho religioso como hecho social: implicancias para el Estado occidental.

en materia política de carácter específico, en un ambiente de diálogo y colaboración, siendo su propósito la promoción de la convivencia de las religiones sin preferencia estatal por alguna de ellas, regulando los aspectos necesarios para que sean vividas en libertad. (Del Picó. 2018).

Por otro lado, por laicismo se puede decir que se ha entendido por aquel "diseño de un Estado absolutamente falto de relación con el fenómeno religioso", marcado por la indiferencia o la neutralidad, y cuyo centro de gravedad sería una no contaminación de los ámbitos sociales por la religión, o, en una visión extrema de una doctrina ligada en su origen al liberalismo en su expresión más confrontativa con la religión y expresiones de fe organizada.

Sus expresiones actuales incluyen principalmente aquellas corrientes que, junto con propugnar la exclusión de los agentes religiosos del escenario público, promueven restricciones generales en materia política que los afectan de manera directa, teniendo como objetivo final "excluir la religión de la vida cultural en lo que tiene de público y común, para confinarla a los reductos de la vida individual". (Traslosheros 2012)

Ahora bien, una propuesta del autor Dianteill (2008) presenta el concepto de laicidad positiva, entendida como la tendencia de la jurisprudencia (refiriéndose al sistema consuetudinario en el derecho estadounidense) que relativiza el predominio del criterio referido a la separación de ámbitos entre el Estado y las confesiones religiosas, marcando una evolución hacia una orientación no teística de la religión, de la mano de factores como la inmigración pluricultural y el intervencionismo estatal.

Por otro lado, expone la propuesta de un concepto de laicidad abierta. Este incluye una idea de neutralidad compatible con la presencia de lo religioso en el ámbito público, al postular que la función del Estado debiera ser la de organizar la diversidad con base en el respeto tanto a los creyentes de las diversas religiones como a las distintas filosofías de vida, incluido el ateísmo.

Al abordar la identificación de los elementos de la noción dominante de Estado laico se debe considerar en una situación central la idea de separación entre los ámbitos propios del Estado y la religión, particularmente sus organizaciones públicas.

Inserción de la relación del Estado con el hecho religioso en el contexto de las democracias occidentales que reconocen el derecho a la libertad religiosa como derecho fundamental. 


\section{Libertad religiosa, la persona jurídica y su relación con el Estado}

Habiendo analizado el reconocimiento del hecho religioso como un hecho social relevante para el Estado, por considerarse como un elemento presente en la sociedad, paso a exponer sobre cuál debería ser la relación entre el Estado, como persona jurídica. El hecho religioso al ser reconocido en su relevancia social requiere de una especial protección en su manifestación jurídica, cual es el goce del derecho a la libertad religiosa.

El respeto y atención por parte del Estado a este hecho social, cual es la religiosidad o la dimensión espiritual del hombre, requiere de mecanismos plasmados en sus leyes y directrices para no perder de vista su misión como Estado, que al reconocerse Laico buscara no desvirtuar su rol de garante de derechos reconocidos en sus leyes nacionales y compromisos internacionales asumidos en contexto de derechos humanos.

Al exigir del estado, adoptar normas y políticas que garanticen derechos, nos induce a reconocer que el derecho a la libertad religiosa se convierte en un principio de orden civil o estrictamente jurídico, cuando se requiere una sistematización legal para su implementación a través del estado.

El hecho generador de esta articulación por parte del Estado es el factor religioso como consecuencia del ejercicio individual y colectivo del derecho a la libertad religiosa a través del cual el individuo ejercita su derecho de una forma concreta, pues es el acto de fe.

La libertad religiosa se vuelve así en un condicionante, que exige del Estado una serie de medidas que respondan ante el fenómeno religioso de sus ciudadanos. Este derecho se garantiza a través de una zona de inmunidad frente al Estado y exige del mismo, una actitud negativa de no intromisión, como así otra actitud positiva, como la promoción y protección del libre ejercicio de esta.

El principio de libertad religiosa ha de precisar la identidad del Estado ante la fe religiosa de la persona y de las confesiones religiosas a través de tres ejes fundamentales:

\section{Libertad religiosa como inmunidad de coacción}

El Estado debe reconocer y garantizar jurídicamente la inmunidad de coacción, es decir que nadie sea obligado a hacer lo que su fe o conciencia le indica no hacer, tanto cuando 
Marcela Bordón Lugo: El hecho religioso como hecho social: implicancias para el Estado occidental.

hablamos de personas individualmente consideraras practicantes, como así a las confesiones, frente a los demás individuos o ante el propio Estado, declarándose incompetente respecto al acto de fe y práctica de la fe religiosa.

Dicha inmunidad se traduce en la imposibilidad para que otras personas particulares, grupos sociales 0 , en general, cualquier potestad humana, puedan interferir en el terreno religioso, obligándola a actuar de manera distinta a los lineamientos de su religión, o impidiéndoles que actúe conforme a ella, en privado y en público, solo o asociados con otros, dentro de los límites debidos.

La no concurrencia en el acto de fe

El Estado debe prohibirse a sí mismo la "concurrencia junto a sus ciudadanos en calidad de sujeto de actos o actitudes ante la fe y la religión, sean del signo que fueren".

El Estado debe considerar ajena a su naturaleza, equiparar su respuesta ante la fe y la práctica religiosa como el de una persona física $y$, al mismo tiempo, no debe confundir absolutamente, esa fundamental incompetencia con alguna forma de expresión o respuesta ante el acto de fe, de forma negativa, agnóstica o indiferente. Tomando un posicionamiento negativo, represivo y prohibitivo, el Estado como ente jurídico estaría tomando una posición equiparada al accionar de un individuo particular, concurriendo con este con un posicionamiento confesional ante una cuestión de fe.

Por tanto, la libertad religiosa, en tanto derecho, impone al Estado la obligación de no coaccionar ni sustituir al individuo ni asumir posicionamientos ante asuntos religiosos en nombre de la mayoría. Sobre cuestiones moralmente conflictuados en la sociedad, como por ejemplo la despenalización del aborto, la pena de muerte o el matrimonio entre personas del mismo sexo, es la herramienta de participación ciudadana la que debe expresar la voluntad de la mayoría, como también el rol de los congresos o parlamentos de los países, quienes están atribuidos de representatividad de la ciudadanía. Pero, el Estado en si mismo, no puede suplantar este ejercicio de participación ciudadana. Es parte del denominado juego democrático, que el Estado se mantenga como árbitro y salvaguarde los debidos procesos que esclarezcan el posicionamiento de la ciudadanía ante ciertos temas conflictivos entre convicciones religiosas y sus diversas interpretaciones o posicionamiento en una sociedad plural.

Lo anterior constituye una acepción negativa del principio de libertad religiosa, porque inhibe la intromisión estatal en asuntos que no son de su competencia. 


\section{Garantía de la libre práctica religioso en la sociedad}

La actividad del Estado en esta cuestión se orienta a la protección y promoción de este derecho al igual que todos los demás derechos fundamentales.

Esta actitud positiva del estado se traduce en el compromiso asumido de proteger el libre ejercicio del derecho a la libertad religiosa y su promoción, rol garante y tutelar jurídico poniendo a disposición, normativas jurídicas que ordenan y organizan determinadas regularizaciones como la inscripción de las entidades de fe en registros, etc. Este compromiso del Estado en la difusión de su rol garante requiere de una condición óptima para el establecimiento del principio de libertad religiosa, la cual obedece al imprescindible carácter democrático del Estado.

En las democracias, puede verificarse un reconocimiento más pleno y una efectiva protección de la libertad religiosa que la contrastada con los sistemas antidemocráticos.

En suma, la libertad religiosa como principio significa que al Estado le compete reducir los obstáculos y promover las condiciones para que la libertad religiosa de los ciudadanos y de los grupos religiosos sea real y efectiva. En virtud de dicho principio rige el imperativo "máxima libertad posible y mínima restricción necesaria", solamente limitado por el mínimum derivado del orden público y seguridad nacional. 
Marcela Bordón Lugo: El hecho religioso como hecho social: implicancias para el Estado occidental.

\section{REFERENCIAS BIBLIOGRÁFICAS}

Cely, B., \& Mauricio, W. (2019). La sociología de la Religión: Una revisión del Estado del arte. https://repositorio.unal.edu.co/handle/unal/10738

Giussani, L. (2008). El sentido religioso. Encuentro.

Rubio, Jorge Del Picó (2018). Estado y religión: tendencias conceptuales incidentes en la apreciación pública del fenómeno religioso. Revista de Estudios Sociales.. Disponible en: https://www.redalyc.org/articulo.oa?id=815/81554612004

Puyol, Á. (2014). Habermas y la religión: Lost in translation. En D. Gamper (Ed.), La fe en la ciudad secular. Laicidad y democracia. Madrid: Trotta.

Dianteill, E. (2008). ¿Hacia una salida de la laicidad en Francia? En F. Mallimaci (Ed.), Religión y política: perspectiva desde América Latina y Europa (pp. 81-92). Buenos Aires: Biblos.

Durkheim, É., Universidad Autónoma Metropolitana, Unidad Cuajimalpa, Universidad Iberoamericana, \& e-libro, C. (2013). Las formas elementales de la vida religiosa el sistema totémico en Australia (y otros escritos sobre religión y conocimiento). Fondo de Cultura Económica.

Bentué, A. (2006). Dios y dioses: Historia religiosa del hombre. Ediciones Universidad Catolica de Chile.

Echegoyen, J. L. C. (1973). Berger, Peter L.; Luckmann, Thomas (1968). La construcción social de la realidad. Papers. Revista de Sociologia, 1(0), 181-183. https://doi.org/10.5565/rev/papers/v1n0.851

Cely, B., \& Mauricio, W. (2019). La sociología de la Religión: Una revisión del Estado del arte. https://repositorio.unal.edu.co/handle/unal/10738 